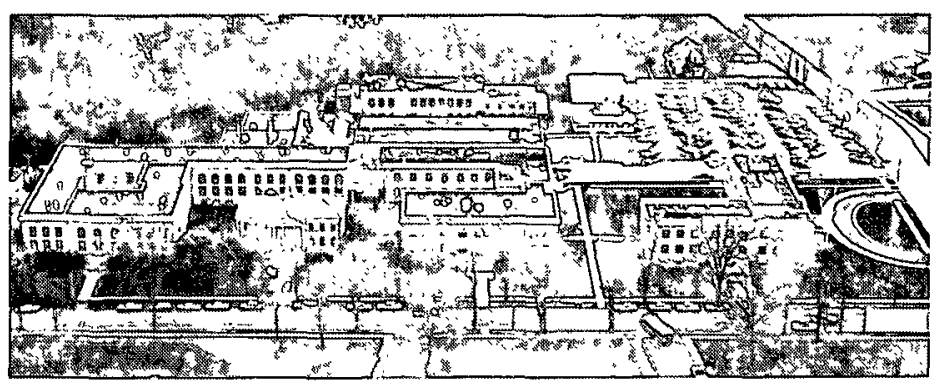

THE INSTITUTE OF PAPER CHEMISTRY, APPLETON, WISCONSIN

IPC TECHNICAL PAPER SERIES

NUMBER 338

\title{
APPARATUS FOR INVESTIGATING BOILING PHENOMENA \\ IN A FIBROUS POROUS MEDIUM
}

GARY R. RUDEMILLER AND JEFFREY D. LINDSAY

JUNE, 1989 


\title{
Apparatus for Studying Boiling in a Fibrous Porous Medium
}

\author{
Gary R. Rudemiller and Jeffrey D. Lindsay
}

\begin{abstract}
Portions of this work were used by GRR as partial fulfillment of the requirements for the $\mathrm{Ph} . \mathrm{D}$. degree at The Institute of Paper Chemistry. This manuscript has been submitted for consideration for publication in International Communications in Heat and Mass Transfer
\end{abstract}

\section{Copyright, 1989, by The Institute of Paper Chemistry}

\author{
For Members Only
}

\section{NOTICE \& DISCLAIMER}

The Institute of Paper Chemistry (IPC) has provided a high standard of professional service and has exerted its best efforts within the time and funds available for this project. The information and conclusions are advisory and are intended only for the internal use by any company who may receive this report. Each company must decide for itself the best approach to solving any problems it may have and how, or whether, this reported information should be considered in its approach.

IPC does not recommend particular products, procedures, materials, or services. These are included only in the interest of completeness within a laboratory context and budgetary constraint. Actual products, procedures, materials, and services used may differ and are peculiar to the operations of each company.

In no event shall IPC or its employees and agents have any obligation or liability for damages, including, but not limited to, consequential damages, arising out of or in connection with any company's use of, or inability to use, the reported information. IPC provides no warranty or guaranty of results. 


\title{
APPARATUS FOR INVESTIGATING BOILING PHENOMENA IN A FIBROUS POROUS MEDIUM
}

\author{
Gary R. Rudemiller ${ }^{1}$ \\ Jeffrey D. Lindsay \\ Engineering Division
}

The Institute of Paper Science and Technology

Atlanta, GA

\section{ABSTRACT}

Recent advances in paper drying research have identified a phase-change process that offers significant improvements in drying rates and sheet solids contents. A fundamental study focusing on the hypothesized boiling process within the sheet required the development of an apparatus to perform boiling experiments in a bed of ceramic fibers. The apparatus is composed of a boiling cell, a heat supply system, a digital data acquisition system, and associated process control systems for control of heater surface temperature and cell pressure. Boiling curves measured with this system indicate that heat transfer is governed largely by the physical characteristics of the fiber bed. This paper presents a detailed explanation of the boiling apparatus.

\section{Introduction}

A novel approach for rapidly drying paper has been developed at The Institute of Paper Science and Technology. In this process, known as impulse drying, wet paper passes through a press nip in which one roll has been heated to 200 to $300^{\circ} \mathrm{C}$. In addition to the normal dewatering achieved by web consolidation in the nip, boiling in the upper layers of the sheet apparently creates a vapor phase which rapidly displaces liquid water from the paper web. Consequently, drying

IPresent address: Westvaco Corporation, Fine Papers Division, P.O. Box 278, Wickliffe, KY 42087. 
rates of 2500 to $7500 \mathrm{~kg} /\left(\mathrm{hr}-\mathrm{m}^{2}\right)$ are typical for impulse drying, which is a dramatic improvement in drying efficiency over conventional pressing and drying operations [1]. With conventional papermaking processes, sheet solids contents prior to the dryer section are typically 40 to $45 \%$, but use of an impulse dryer can raise this to 60 to $65 \%$. This improvement in water removal efficiency offers the potential to reduce the energy consumed to dry the moist sheet by $50 \%$ [2]. Figure 1 illustrates the impulse drying process.

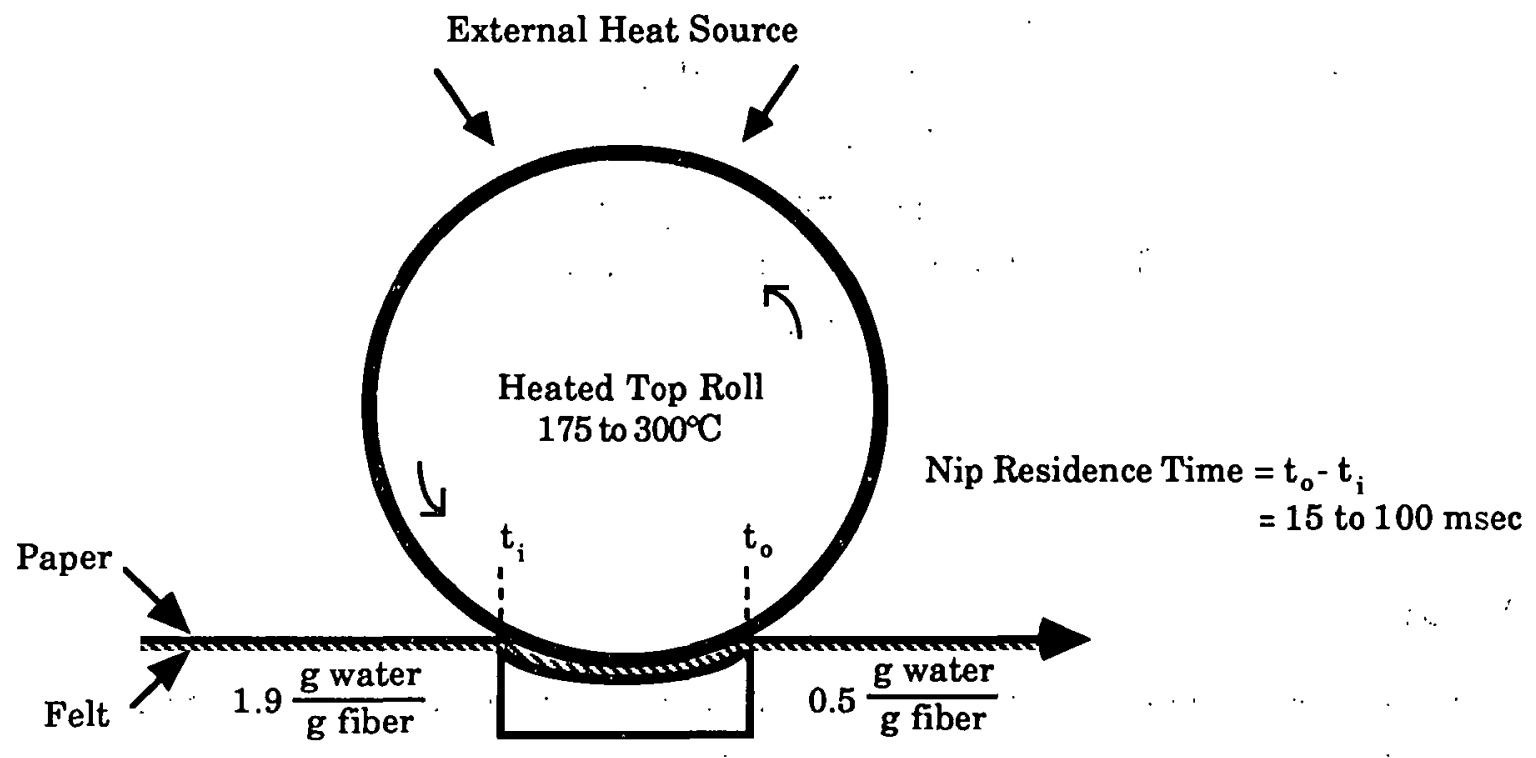

Long Nip Press

3 to $5 \mathrm{MPa}$ peak pressure

Fig. 1. A schematic of the impulse drying process.

During the 15 to $100 \mathrm{msec}$ impulse drying event, heat fluxes on the order of 1 to $5 \mathrm{MW} / \mathrm{m}^{2}$ are observed. Though some vapor is generated, as much as $90 \%$ of the water that is removed from the sheet leaves in liquid form, making impulse drying much more effective than evaporative drying. Little knowledge exists concerning the boiling process that is hypothesized to occur in the fibrous sheet next to the heated roll. The interaction of phase-change heat transfer with a porous, compressible fiber mat offers many avenues for research, and an understanding of these processes is important for the commercial implementation of impulse drying.

\section{Background}

Boiling in the presence of liquid-saturated porous media has received much attention from. the research community in recent years. Technological applications include high-flux heat transfer surfaces, heat pipes, post-accident heat removal from liquid-cooled nuclear reactors, and heat recovery from geothermal reservoirs [3-6]. Many studies in the generic area of boiling in porous media actually address the convective patterns within the porous bed induced by phase 
change [3,4,7-9]. Within liquid-saturated porous beds that possess appreciable capillary forces and which are heated from below, phase-change heat transfer results in the development of an isothermal; two-phase zone with a height directly proportional to heat flux. Vapor generated at the heater surface flows upward under the influence of a slight vapor pressure gradient and buoyant forces, and water flows down to replenish the heater surface under the influence of capillary forces. This counterpercolation mechanism transfers heat through the porous medium as the vapor condenses at the upper boundary of the two-phase zone.

The impact of the porous medium on the complete boiling curve has not been researched extensively. The previously-cited studies involve low-intensity heat transfer at wall superheats representative of the nucleate regime in classical pool boiling, while higher superheats have generally been neglected. The current study is an investigation of steady-state boiling phenomena in model porous media that possess appreciable capillary forces for the purpose of determining the characteristic boiling curves. An experimental control system consisting of the boiling cell apparatus, electronic instrumentation, data acquisition equipment, computer software, and process control hardware have been assembled for execution of a boiling experiment. This paper details the apparatus and the control scheme used to determine the characteristic curves for boiling in a fibrous medium.

\section{The Experimental Apparatus}

Determining the characteristic curve for boiling in a fibrous medium requires measurement of heat flux and surface temperature data. The experimental apparatus designed to gather the data, illustrated in Figure 2, is composed of four systems: the boiling cell, the heat supply system, the data acquisition system, and the process control system. The apparatus is designed to study heating block surface temperatures up to $400^{\circ} \mathrm{C}$ and cell pressures up to $0.3 \mathrm{MPa}$. The beds are composed of ceramic fibers with diameters of $3.0,8.4$, or $18.5 \mu \mathrm{m}$. Porosities range from 0.93 to 0.96 ; permeabilities range from $10^{-11}$ to $10^{-9} \mathrm{~m}^{2}$, and average pore diameters (as determined from capillary pressure functions $[10,11])$ range from 40 to $250 \mu \mathrm{m}$.

\section{The Boiling Cell}

The boiling cell consists of a 9-cm ID x 110-cm long machined quartz cylinder that houses the fiber bed. The fiber bed is formed within one end of the tube by filtration from a slurry having a consistency of approximately $0.1 \%$. After formation, up to six fine-gage thermocouples are embedded within the fiber bed to gather information about thermal patterns that develop as the boiling process proceeds. The thermocouples are mounted with thermocouple fittings to half-inch OD quartz nipples welded to the wall of the quartz tube. The tube is axially compressed between the heating block and a top mounting plate to seal the system for pressurized boiling. 


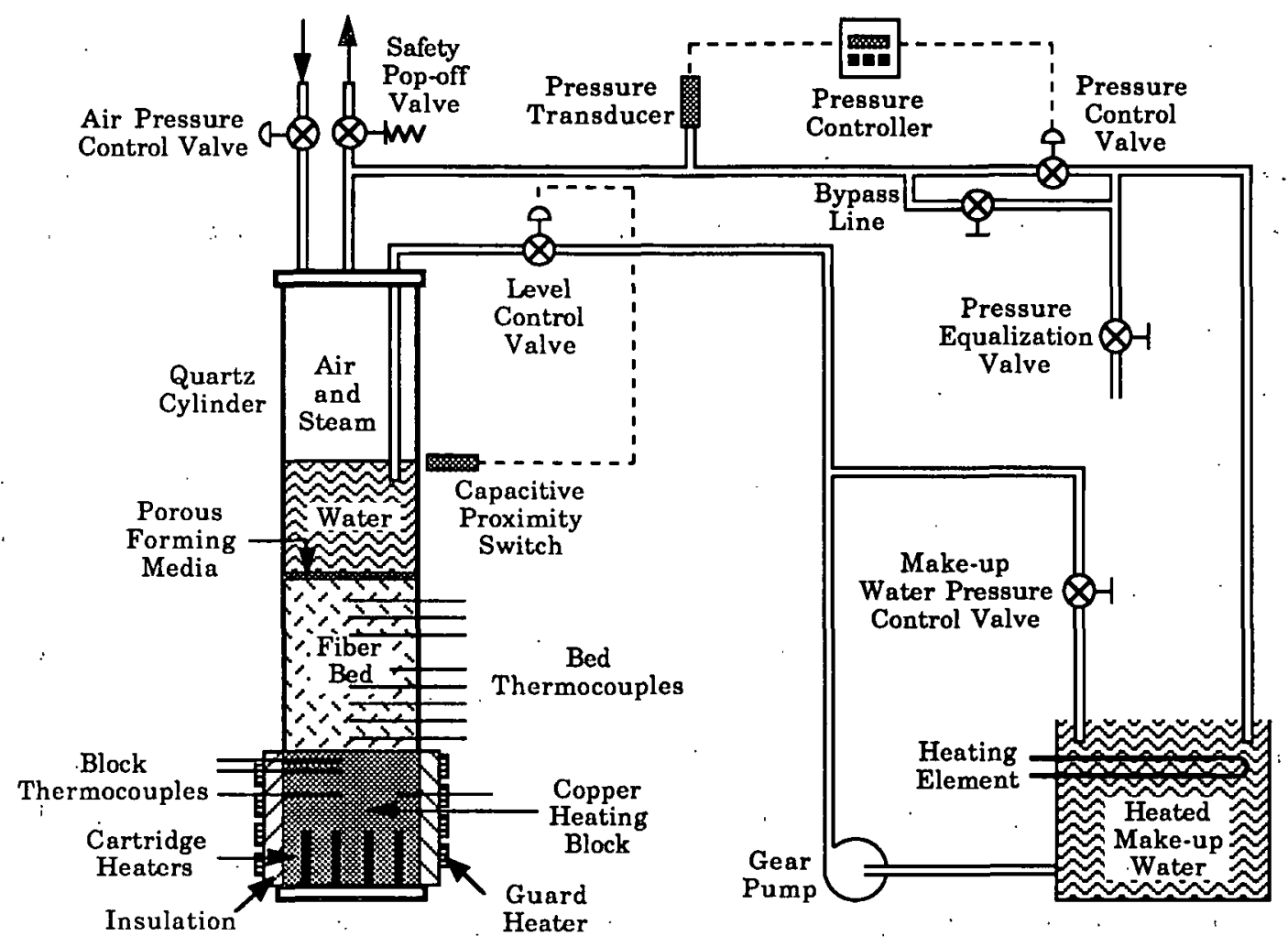

Fig. 2. A schematic of the boiling cell apparatus.

\section{The Heat Supply System}

The heating block, which is machined from a copper-tellurium alloy (ASTM B145), is 17.8 $\mathrm{cm}$ in length by $10.2 \mathrm{~cm}$ in diameter. Thermocouples embedded within the block in proximity to the boiling surface provide the data necessary to determine surface temperature and heat flux. The junctions of three thermocouples positioned in similar radial positions are located at distances of $0.318,0.635$, and $1.27 \mathrm{~cm}$ from the surface of the heating block. A fourth thermocouple is positioned $1.27 \mathrm{~cm}$ from the heating surface, but in a different radial position to check onedimensionality of heat flow. Surface temperature is calculated rather than measured because any surface nonuniformity (such as that caused by the presence of a surface thermocouple) significantly disrupts the character of the boiling process. Because the thermal conductivity of the copper material varies significantly over the experimental temperature range, heat flux is determined from the one-dimensional heat diffusion equation incorporating the curve-fitted expression for temperature-dependent thermal conductivity.

To ensure one-dimensional heat flow, convective heat losses are minimized by wrapping the heating block with $4.5-\mathrm{cm}$ thick $\mathrm{CaSiO}_{4}$ insulation, and by wrapping the insulation with a guard heater. The temperature of the guard heater is controlled to match the average temperature of the thermocouples in the top region of the block. Nine cartridge heaters positioned symmetrically 
in a vertical orientation in the bottom of the heating block provide the heat for boiling. A siliconcontrolled rectifier (SCR) meters electrical current to the heaters based on a 4 to 20 -mA signal from the temperature controller. The electrical supply to the heaters is sized for $40 \mathrm{~A}$ at $240 \mathrm{~V}$ to supply a maximum of $9000 \mathrm{~W}$ of heat over a heater surface area of $63.2 \mathrm{~cm}^{2}$. The surface temperature control scheme is discussed below.

\section{Data Acquisition System}

A number of Type-K thermocouples and one strain-gage pressure transducer used for data acquisition and control purposes are interfaced with a data acquisition system consisting of electronic boards manufactured by Metrabyte Corporation. A DAS16F high speed A/D I/O board, mounted on the motherboard of an AT-compatible computer, is connected to two external, daisychained EXP16 universal expansion submultiplexer boards via an STA-U universal terminal board. The EXP16 boards, which are equipped with cold-junction compensation circuitry to reference the thermocouple voltages, read the analog millivoltage signals from the thermocouples and amplify them to 0 to $5 \mathrm{~V}$ for input to the DAS16F. The 0 to $5-\mathrm{V}$ output of the pressure transducer is fed to the DAS16F via connections at the STA-U board, and also is fed directly to the pressure controller as the process variable. Metrabyte provides software drivers and subroutines for interfacing the data acquisition equipment with different computer languages. Control software was written to operate the apparatus with an AT-compatible computer as the system host. TBASIC $^{\otimes}$, a version of BASIC, was selected as the programming language because of its speed and its interactive editor mode. This required a rewrite of Metrabyte's assembler driver to make the data acquisition system compatible with TBASIC ${ }^{\otimes}$.

\section{The Process Control System}

The experimental control system developed for this apparatus provides data acquisition, pressure control, and heater block surface temperature control, as illustrated in Figure 3. Water level in the cell is controlled simply by interfacing a capacitive proximity switch with a normallyopen solenoid valve to meter flow of heated make-up water, and does not interact with the other components of the control system.

The Surface Temperature Control System

The temperature of the boiling surface of the copper heating block is one of the controlled variables for the boiling experiment. Since minimal instabilities are encountered in this boiling study, adequate control is maintained throughout the experiment with a standard PID controller, rather than the complex systems needed for control of classical pool boiling studies that utilize surface temperature as the control variable [12-15].

As previously mentioned, the temperature of the heater surface is calculated from the readings of three thermocouples positioned within the heater block in proximity to the boiling surface. To facilitate control of surface temperature, the control software interfaces with the data 


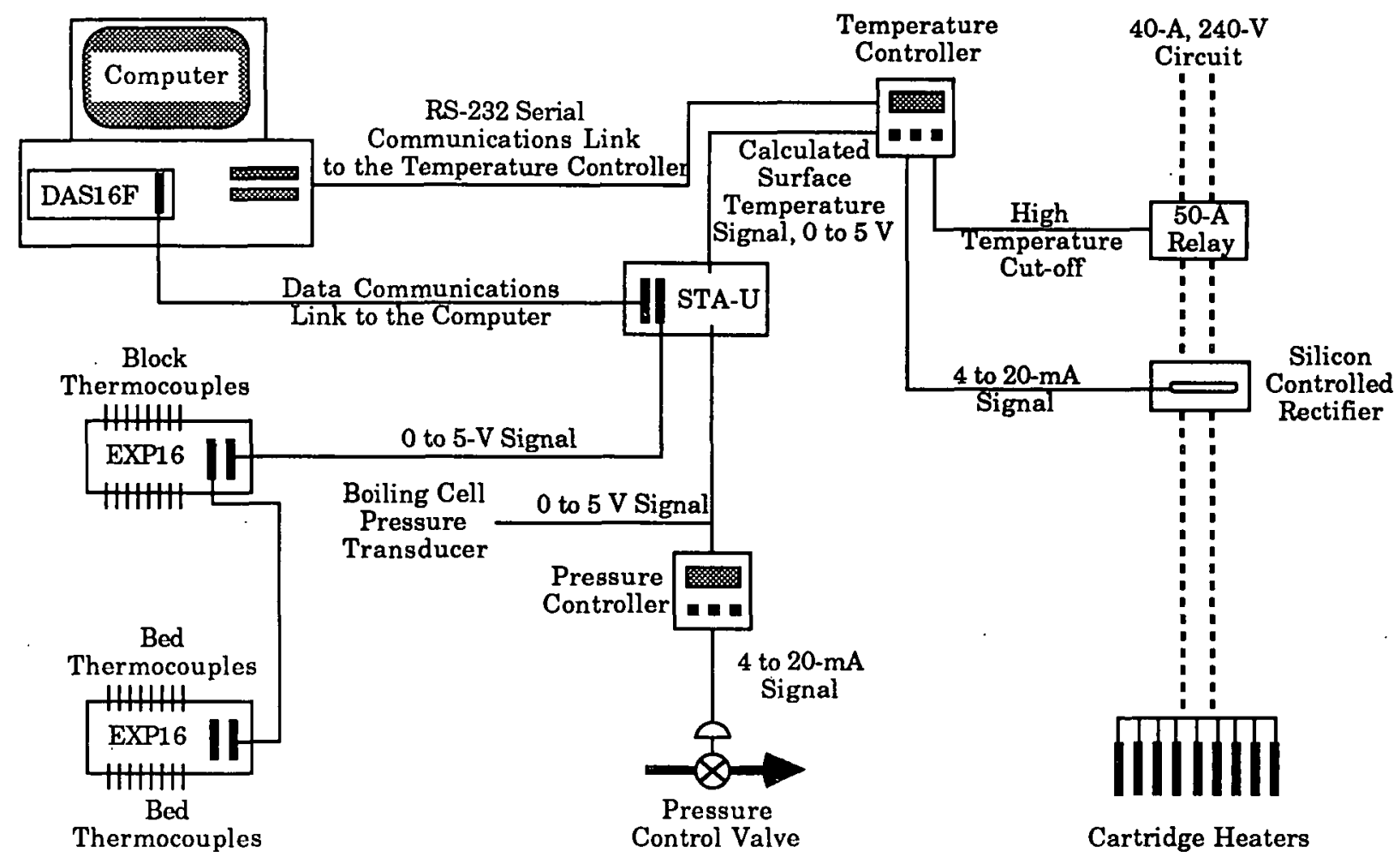

Fig. 3. A schematic of the interface between the data acquisition and process control systems.

acquisition system and the temperature controller. The main function of the software is to continuously read the analog signals from the block thermocouples via the data acquisition equipment, extrapolate the block surface temperature based on a linear regression of the three block thermocouples, and download this temperature as a 0 to $5-\mathrm{V}$ analog signal to the temperature controller via one of the D/A channels of the DAS16F. This sequence forms a loop that cycles continuously while the experiment is active to provide a process input to the temperature controller about once per second. In this fashion, the computer provides a calculated process input to the temperature controller.

An LFE Model 2012 PID controller with ramp/soak capabilities is used to control the surface temperature of the heater block. The 4 to $20-\mathrm{mA}$ output of the controller actuates the SCR to meter electric current to the cartridge heaters. A high-temperature-alarm relay is connected to an in-line 50-A relay to cut off electric current if the surface temperature exceeds a defined upper limit. Because the thermal mass of the copper heating block is very large, process dynamics exhibit a lag time on the order of 90 seconds. Acceptable control is accomplished with proportional, integral, and derivative control actions.

In these experiments, data are collected at a given surface temperature after the process reaches steady state. Because the location of the transition points in the boiling curve are not known a priori, surface temperature setpoints are approached in a slow, orderly fashion by 
utilizing the ramp/soak capabilities of the controller. Although it would be convenient to program the ramp/soak profiles for the entire experiment prior to starting, the sensitivity of boiling phenomena prevents determination of the subsequent temperature setpoint until the present setpoint is achieved. This limitation is handled by selecting the surface setpoint increment, ramp rate, and soak time at appropriate times during the experiment, and by downloading this information from the computer to the controller via an RS232 serial communications link. The Pressure Control System

A Partlow MIC 6000 PID controller is used to control cell pressure. The 0 to $5-\mathrm{V}$ signal from the pressure transducer located on the vapor vent line is fed to the controller and to the DAS16F for data acquisition. The 4 to $20-\mathrm{mA}$ output of the controller actuates a pneumatic control valve. No controller alarms are utilized. Because the response of this loop is nearly instantaneous, no derivative action is required.

\section{Results}

After forming the fiber bed in the boiling cell, the apparatus is assembled and prepared for a boiling experiment. The experiment is initiated from a room temperature, quiescent state by slowly heating to a surface temperature about $7^{\circ} \mathrm{C}$ above the system saturation temperature, where the process is held in a boiling state for about one hour. Then, the initial desired surface temperature setpoint and its associated ramp rate are selected and downloaded to the temperature controller. Due to the potential for process instabilities and the thermal lag in the heating block; the setpoints are approached slowly, generally on the order of $1.5^{\circ} \mathrm{C}$ per minute. After the process has stabilized, a complete set of data is collected via the computer control software at the prompt of the operator. The experiment is continued by selecting and downloading the new setpoint and ramp rate information. The magnitudes of the selected temperature increment and ramp rate are based on sensitivity of the region of the boiling curve being approached. Completion of a boiling curve requires approximately five hours.

To determine the characteristic boiling curve, surface temperature and heat flux data are needed. Both are determined from the one-dimensional heat diffusion equation with temperaturedependent thermal conductivity. Uncertainty analysis indicated that heat flux calculations based on the thermocouples closest to and furthest from the heater surface yield heat fluxes accurate to within $0.9 \mathrm{~W} / \mathrm{cm}^{2} \mathrm{ADD}$, and $0.7 \mathrm{~W} / \mathrm{cm}^{2} \mathrm{RMS}$. Surface temperature is accurate to within $0.6^{\circ} \mathrm{C}$ $\mathrm{ADD}$, and $0.4^{\circ} \mathrm{C}$ RMS.

Typical boiling curves collected at different pressures with the experimental system are illustrated in Figure 4 [16]. The curve exhibits two boiling regimes and a point of transition between them that represents the peak heat flux attained during the experiment. These curves were selected from the available data because they illustrate the interesting behavior associated with the transition between the two regimes. The initial regime is similar to the nucleate boiling regime of 


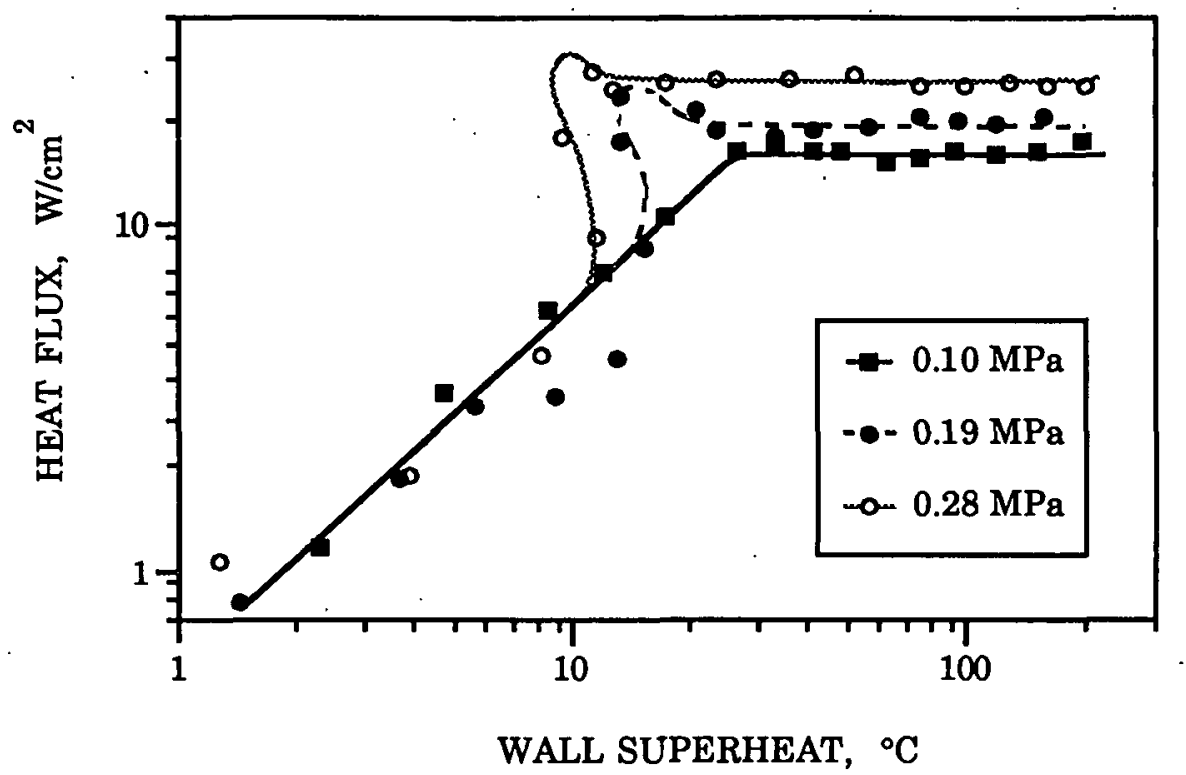

Fig. 4. Boiling curves at different pressures for water in a fibrous bed with an average pore diameter of $250 \mu \mathrm{m}$.

classical pool boiling, as the heat flux increases with wall superheat. Apparently, some form of active nucleation is occurring at voids on the heater surface. During this nucleate-type regime, an isothermal, two-phase zone develops within the fibrous bed at the heater surface, and grows as heat flux increases until the entire bed is engulfed in two-phase flow. Vapor generated at the heater surface flows upward under the influence of a partial pressure gradient, and liquid flows down to the heater surface under the influence of capillary forces and gravity. Temperature measurements at various locations within the bed indicate that the entire height of the two-phase zone is isothermal. Below the region of transition, this nucleate-type regime appears to be insensitive to the moderate range of pressures examined.

In the second regime, the heat flux is totally independent of wall superheat. Heat flux is controlled by the rate of liquid flow to the heater surface under the influence of capillary forces of the bed. Obviously, this depends on the saturation level and pore size distribution of the bed. The magnitude of heat flux in this regime increases with pressure, due in part to higher bed saturations achieved with increased vapor-phase density.

The point of transition between the two regimes, or the critical heat flux (CHF), is potentially an unstable condition that requires prompt action by the surface temperature control system. At the CHF, beds with average pore diameters greater than about $175 \mu \mathrm{m}$ experience some change in the fluid flow phenomena within the fiber bed that apparently reduces the heat-absorbing capacity of the bed. Attempts to increase surface temperature beyond the CHF yield an instantaneous, rapid rise in surface temperature (typically, an increase of 10 to $15^{\circ} \mathrm{C}$ ). until the control system arrests the rise. Frequently, the process must be returned to a lower temperature, as 
the rise often overshoots the desired setpoint. Conversely, beds with average pore diameters below about $90 \mu \mathrm{m}$ exhibit a smooth transition between regimes, with no apparent critical heat flux, at all pressure levels examined. With the available fiber diameters, it is not possible to form beds with average pore diameters between 90 and $175 \mu \mathrm{m}$ in this apparatus.

For large pore diameter beds, the degree of instability experienced at the critical heat flux is dependent on the pore size of the bed, and on the system pressure. At atmospheric pressure, these beds exhibit a peak heat flux with a magnitude greater than that of the iso-heat flux regime. The phenomena associated with the critical heat flux are experimentally observed to be very sensitive, as more scatter is apparent in the thermocouple readings at process points near the CHF. This slight instability is exacerbated at higher pressures. As the process nears the critical heat flux under pressure, the system stabilizes, with increasing difficulty, at successively lower wall superheats, which is exhibited as a backward bend in the boiling curve, until finally, the process . peaks and the surface temperature rapidly escalates. This behavior of decreasing wall superheat at increased levels of heat flux is reproduced in all of the pressurized boiling runs for beds with average pore diameters above about $175 \mu \mathrm{m}$.

\section{Conclusions}

The experimental control system operates effectively to allow trouble-free execution of a steady-state boiling experiment. The method of extrapolating surface temperature of the heating block based on readings from thermocouples embedded within the block provides an accurate measure for control purposes, but maximum accuracy requires that the one-dimensional heat diffusion equation with temperature-dependent thermal conductivity be used in conjunction with the calculated heat flux to give a more accurate indication of surface temperature. Characteristic curves for boiling in a porous medium exhibit a nucleate-type regime, an iso-heat-flux regime, and a region of transition between them. Fortunately, the instability associated with the CHF of large-pore-diameter beds is not extensive, so a relatively simplistic process control system gives acceptable control of surface temperature. A forthcoming paper will discuss the results of this investigation in detail.

\section{Acknowledgments}

The authors would like to specifically thank Kurt Lorenz, Rich Mirabello, Doug Wheeler, Glenn Winkler, and Paul Van Rossum for their expert assistance in assembling the apparatus. This work was supported by the U.S. Department of Energy (Contract No. DE-FGO2-85CE407238) and by the member companies of The Institute of Paper Science and Technology. This support is gratefully acknowledged. Portions of this work were used by G. R. as partial fulfillment of the requirements for the $\mathrm{Ph} . \mathrm{D}$ : degree at The Institute of Paper Science and Technology.

\section{Bibliegraphy}

1. Sprague, C.H. Impulse Drying and Press Drying: A Critical Comparison. Proceedings of the 
Tappi Papermakers Conference. Atlanta, GA, April 6-7, 1987:35-41.

2. Sprague, C.H.; Lavery, H.P. Impulse Drying: A Status Review. XXIII EUCEPA Conference. Harrogate, UK, May 31-June 3, 1988.

3. Sondergeld, C.H.; Turcotte, D.L. An Experimental Study of Two-Phase Convection in a Porous Medium with Applications to Geological Problems. Journal of Geophysical Research 82(14):2045-2053(May 10, 1977).

4. Schubert, G.; Straus, J.M. Steam-Water Counterflow in Porous Media. Journal of Geophysical Research 84(B4):1621-1628(April 10, 1979).

5. Costello, C.P.; Redeker, E.R. Boiling Heat Transfer and Maximum Heat Flux for a Surface with Coolant Supplied by Capillary Wicking. AIChE Chemical Engineering Progress Symposium Series 59(41):104-113(1963).

6. Barthelemy, R.R. Evaporation Heat Transfer in Heat Pipes. Proceedings of the $2^{\text {nd }}$ International Heat Pipe Conference:425-436, Bologna, Italy(1976).

7. Bau, H.H.; Torrance, K.E. Boiling in Low-Permeability Porous Materials. International Journal of Heat and Mass Transfer 25(1):45-55(January 1982).

8. Bau, H.H.; Torrance, KE. Thermal Convection and Boiling in a Porous Medium. Letters in Heat and Mass Transfer 9(6):431-441(November-December 1982).

9. Udell, K.S. Heat Transfer in Porous Media Considering Phase Change and Capillarity The Heat Pipe Effect. International Journal of Heat and Mass Transfer 28(2):485-495(February 1985).

10. Bruce, W.A.; Welge, H.J. The Restored-State Method for Determination of Oil in Place and Connate Water. Drilling and Production Practices, American Petroleum Institute, pgs. 166-174(1947).

11. Dullien, F.A.L. Porous Media: Fluid Transport and Pore Structure. Academic Press, New York, pg. 21 (1979).

12. Peterson, W.C.; Zaalouk, M.G. Boiling-Curve Measurements from a Controlled Heat-Transfer Process. Journal of Heat Transfer 93:408-412(November, 1971).

13. Peterson, W.C.; Thacker, A.; Avery, W.L. A Feedback System for Control of an Unstable Process. IEEE Transactions on Industrial Electronics and Control Instrumentation, IECI-16(2):165-171(September, 1969).

14. Peterson, W.C.; Zaalouk, M.G.; Goetze, A.J. Development and Evaluation of Transfer Functions for Nucleate, Transition, and Film Boiling. Journal of the Franklin Institute 285(4):285-296(April, 1968).

15. Gentile, D.; Llory, M. An Experimental Investigation of the Boiling Crisis in a Forced Convection Freon 113 Flow. ASME Winter Annual Meeting Proceedings:77-83, Miami Beach, FL(November 17-22, 1985).

16. Rudemiller, G.R. A Fundamental Investigation of Boiling Heat Transfer Mechanisms Related to Impulse Drying. Doctoral Dissertation, The Institute of Paper Science and Technology, Atlanta, GA, 1989. 